\title{
ECONOMIC AND KINETIC STUDIES OF THE PRODUCTION \\ OF CHEMICALS AND FARM ENERGY BY FERMENTATION OF BIOHASS
}

\author{
J. L: Gaddy \\ University of Missouri-Rolla
}

\section{MASTER}

\section{FARM ENERGY SYSTEM}

The farm energy system, shown schematically in Figure 1, has been constructed on a farm in Drury, Missouri. The purpose of this unit is to demonstrate the feasibility of producing. energy for farms (heat and electricity) from methane produced by anaerobic digestion of crop residues and other crop materials.

The system consists of four 4,000 gallon digestors equipped with axial agitators. The reactors are housed in an insulated building maintained at $95^{\circ} \mathrm{F}$. Crop matter is fed to the digestors on a sixty-day batch cycle. Methane produced is stored in PVC bags and used to generate electricity or for heat in the farmhouse. Waste heat from the engine-generator is used to heat the building.

The system was started in early summer by inoculating five percent haywater mixtures with sewage sludge. Start-up went smoothly with gas production reaching a maximum within two weeks, as shown in Figure 2 . Control of $\mathrm{pH}$ required frequent lime addition during the first week, but lime additions were not necessary after this period to maintain $\mathrm{pH}>7$. Methane concentrations were between 45 and 65 percent and averaged above 50 percent. After sixty days carbon destruction was 50 percent. 


\section{DISCLAIMER}

This report was prepared as an account of work sponsored by an agency of the United States Government. Neither the United States Government nor any agency Thereof, nor any of their employees, makes any warranty, express or implied, or assumes any legal liability or responsibility for the accuracy, completeness, or usefulness of any information, apparatus, product, or process disclosed, or represents that its use would not infringe privately owned rights. Reference herein to any specific commercial product, process, or service by trade name, trademark, manufacturer, or otherwise does not necessarily constitute or imply its endorsement, recommendation, or favoring by the United States Government or any agency thereof. The views and opinions of authors expressed herein do not necessarily state or reflect those of the United States Government or any agency thereof. 


\section{DISCLAIMER}

Portions of this document may be illegible in electronic image products. Images are produced from the best available original document. 


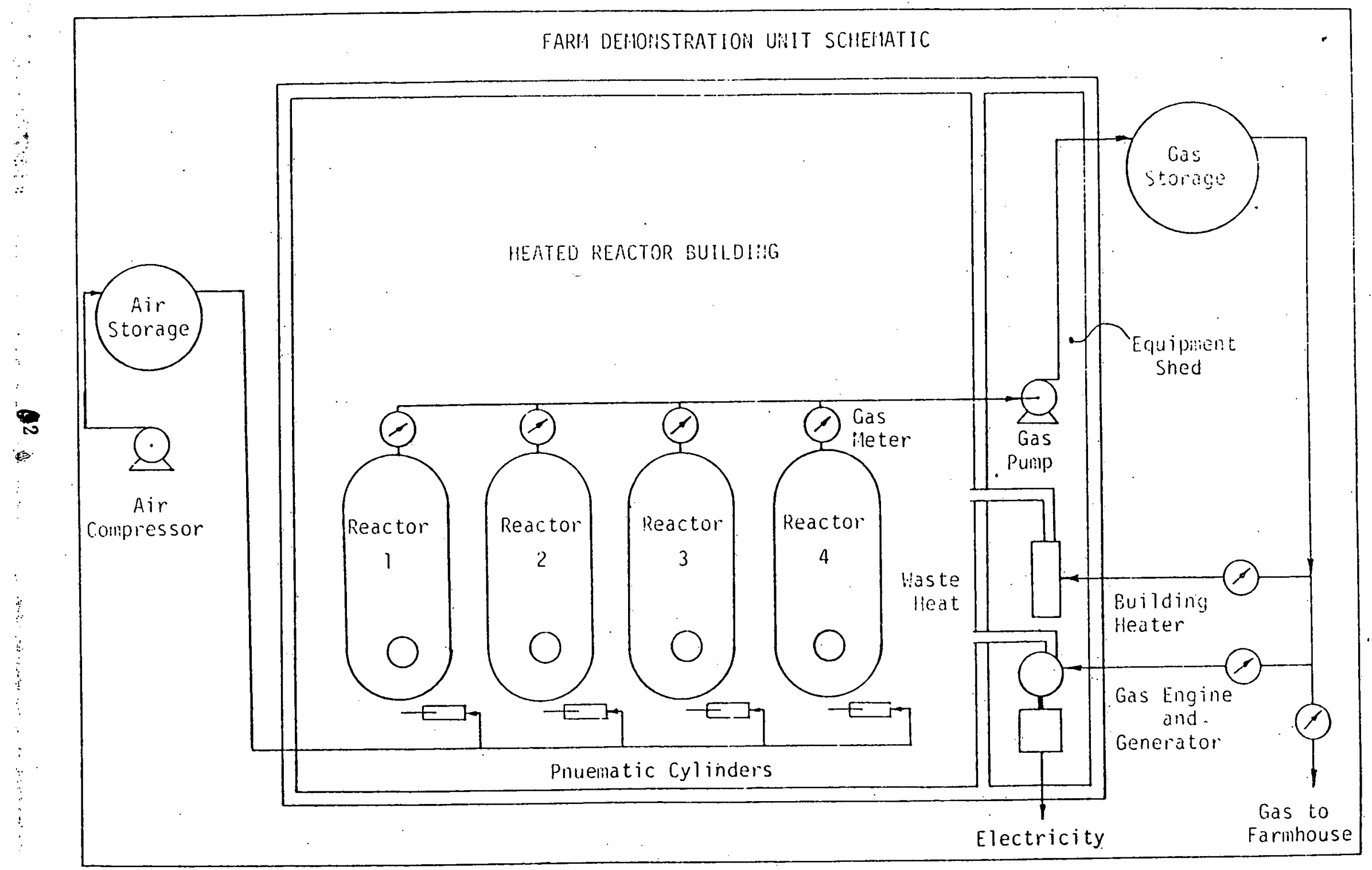

Figure 1. Schematic of Farm System 


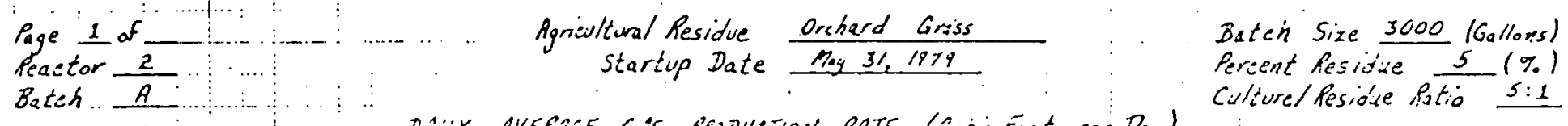

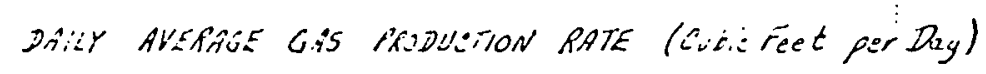

Perient Residue 5 (\%) Culturel Resióke Ratio s:1

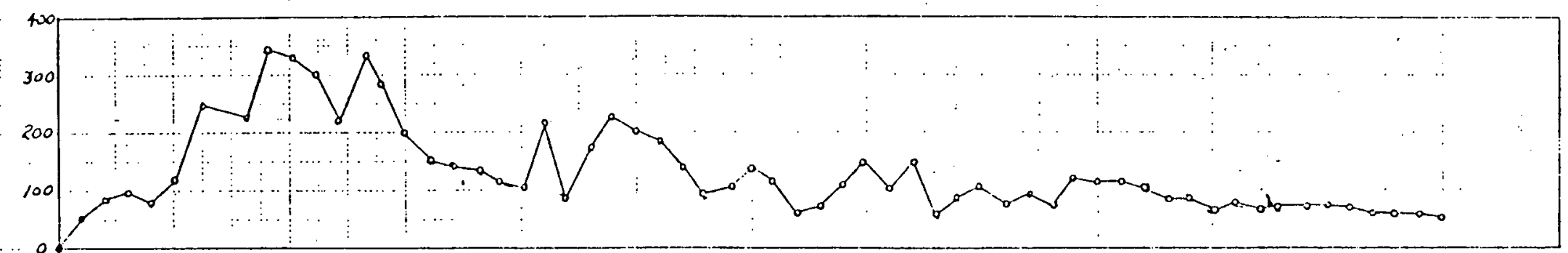

C.4 30 D DESTRUCTON (\%)
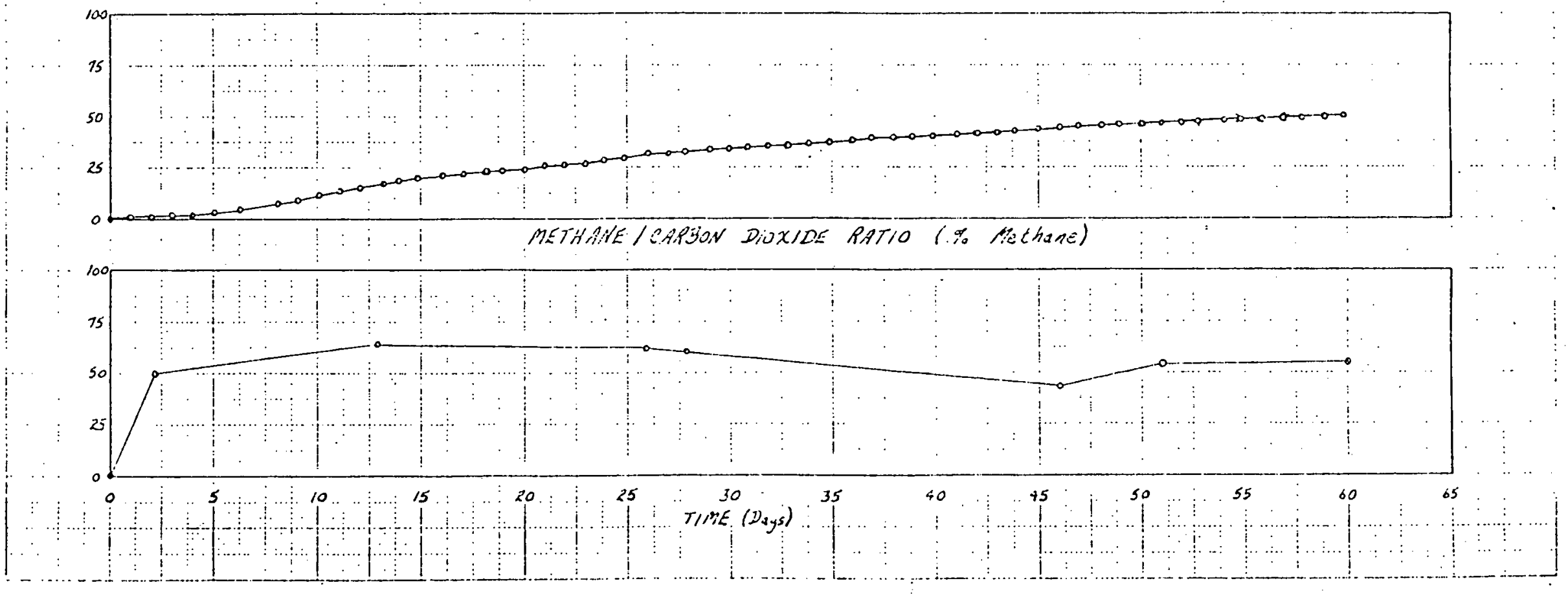

Figure 2. Farm Reactor Data 
The performance of batch laboratory reactors using the same hay as the farm system is shown in Figure 3. These laboratory reactors are operating with ten percent hay initially and three cycles of several weeks duration are shown. Each cycle is re-inoculated from the previous culture. The same performance cycle as the farm reactors is apparent. with maximum gas production occurring after two weeks. Carbon destructions have been poor, but improve with each cycle. Methane concentrations are consistently above 50 percent. These lab reactors are operated to determine the best inoculation sequence for the farm reactors and to study possible problems with culture nutrient deficiencies and aging.

The initial agitator drive mechanism consisted of two pneumatic cylinders driving all four agitators through a linkage shaft. This concept minimized. the energy input, but introduced severe mechanical problems with proper alignment. This system is presently being modified with a pneumatic cylinder on each reactor. Since only periodic agitation will be used, the additional energy consumed will not be excessive.

The engine-generator has been installed and satisfactorily tested with biogas. A $10 \mathrm{hp}$ induction motor is used as the generator. Negotiations with the local utility for the sale of electricity are underway.

Three replications of field plots were established at the Southwest Center near Mt. Vernon, Missouri, in order to evaluate cropping mixtures for biomass production. Each plot is 30 by 100 feet so that enough material will be produced for evaluation of methane production in pilot studies. Treatments include double cropping winter rye and sorghum-sudan or corn, intercropping tall fescue and red clover or alfalfa or orchardgrass, and monoculture of warm-season perennials such as caucasian bluestem and indiangrass. Plots 

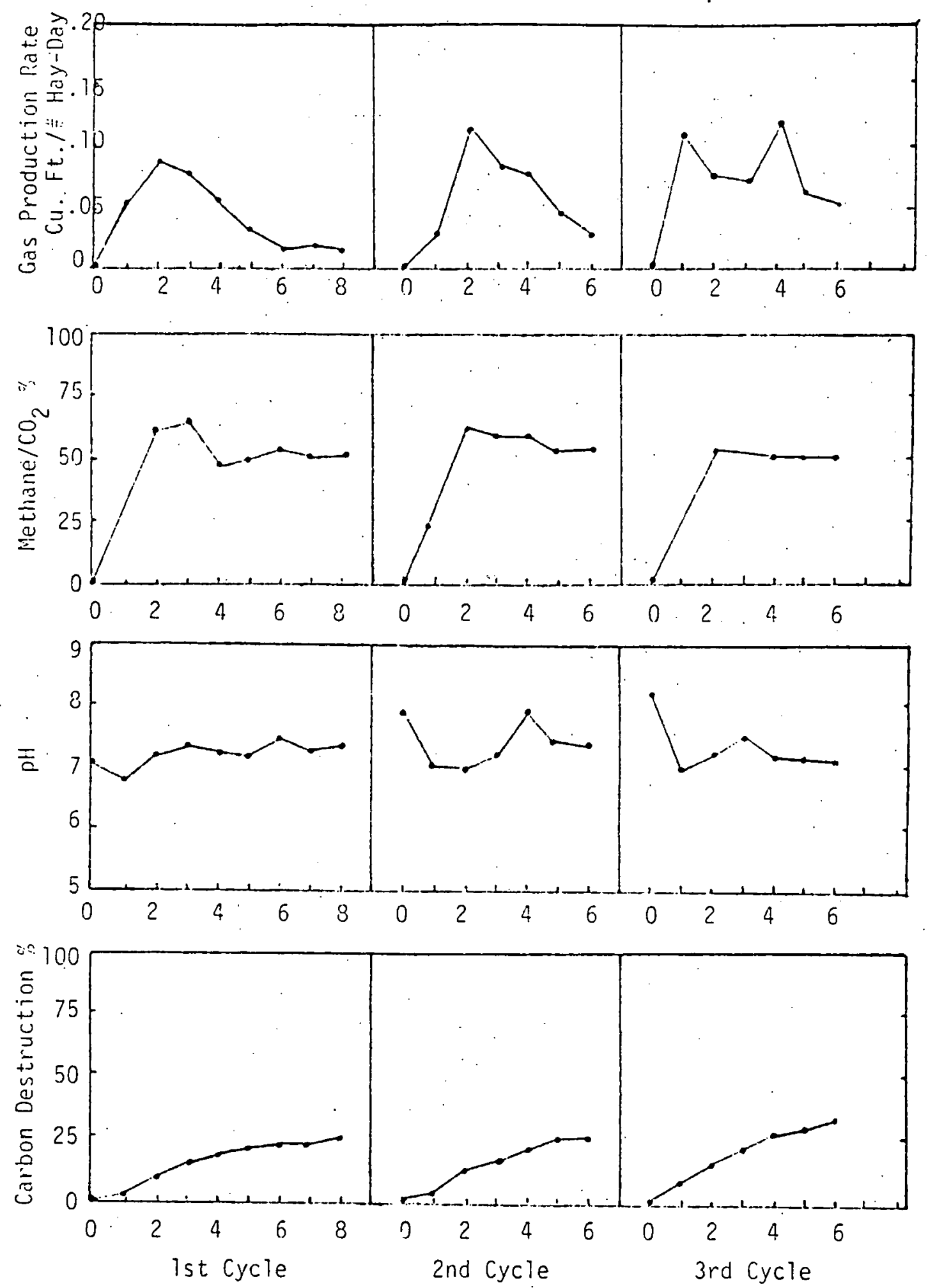

TIME (Weeks)

Figure 3. Laboratory Digestor Performance 
of the rye component and the cool-season forage mixtures were seeded this fall. The warm-season annuals and perennials will be seeded next spring.

\section{ACID HYDROLYSIS/FERMENTATION STUDIES}

The acid hydrolysis pre-treatment of corn stover studies utilize a two stage sulfuric acid contact. "In the first stage, dilute sulfuric acid is used to hydrolyze the pentosan fraction of ground biomass. The second stage uses concentrated sulfuric acid for hexosan hydrolysis. The use of the two steps give high yields, possible with concentrated acid, without the problems of pentose decomposition.

Figure 4 gives a typical concentration profile for the pre-hydrolysis step. This hydrolysis is carried out at $98^{\circ} \mathrm{C}$ with 4.4 percent acid. Figure 5 gives the profile for the second stage with 85 percent acid also at $98^{\circ} \mathrm{C}$. As noted, only small quantities of glucose are produced in the pre-hydrolysis. No xylose is present in the hydrolyzote, indicating complete conversion of pentosans in the pre-hydrolysis.

A series of studies is being conducted to determine the optimal temperatures, acid concentrations and reaction times for both steps. Fermentation of the hydrolyzate fractions will begin when these studies are completed. 


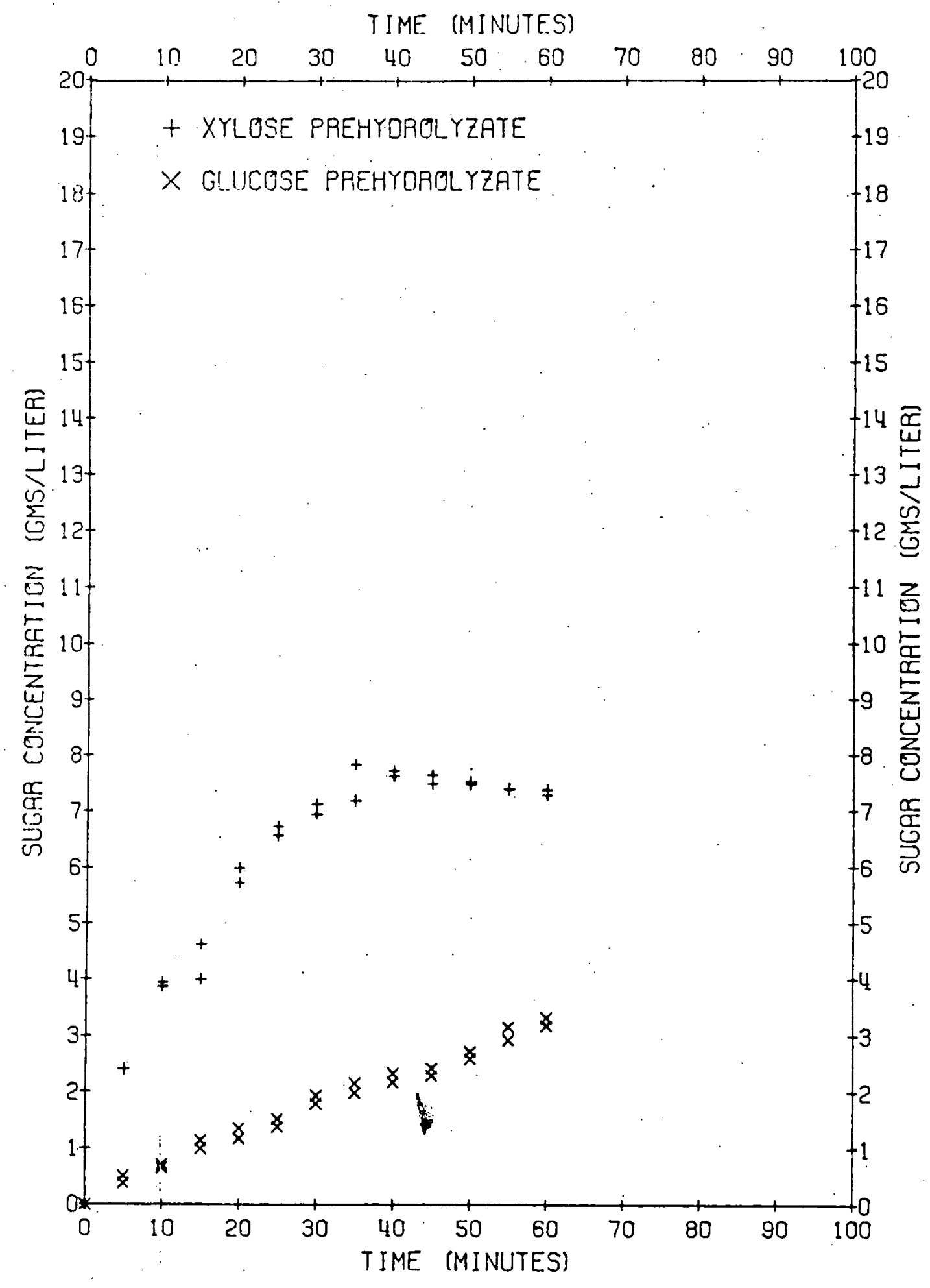

Figure 4. Sugar Formation in Prehydrolysis Step 


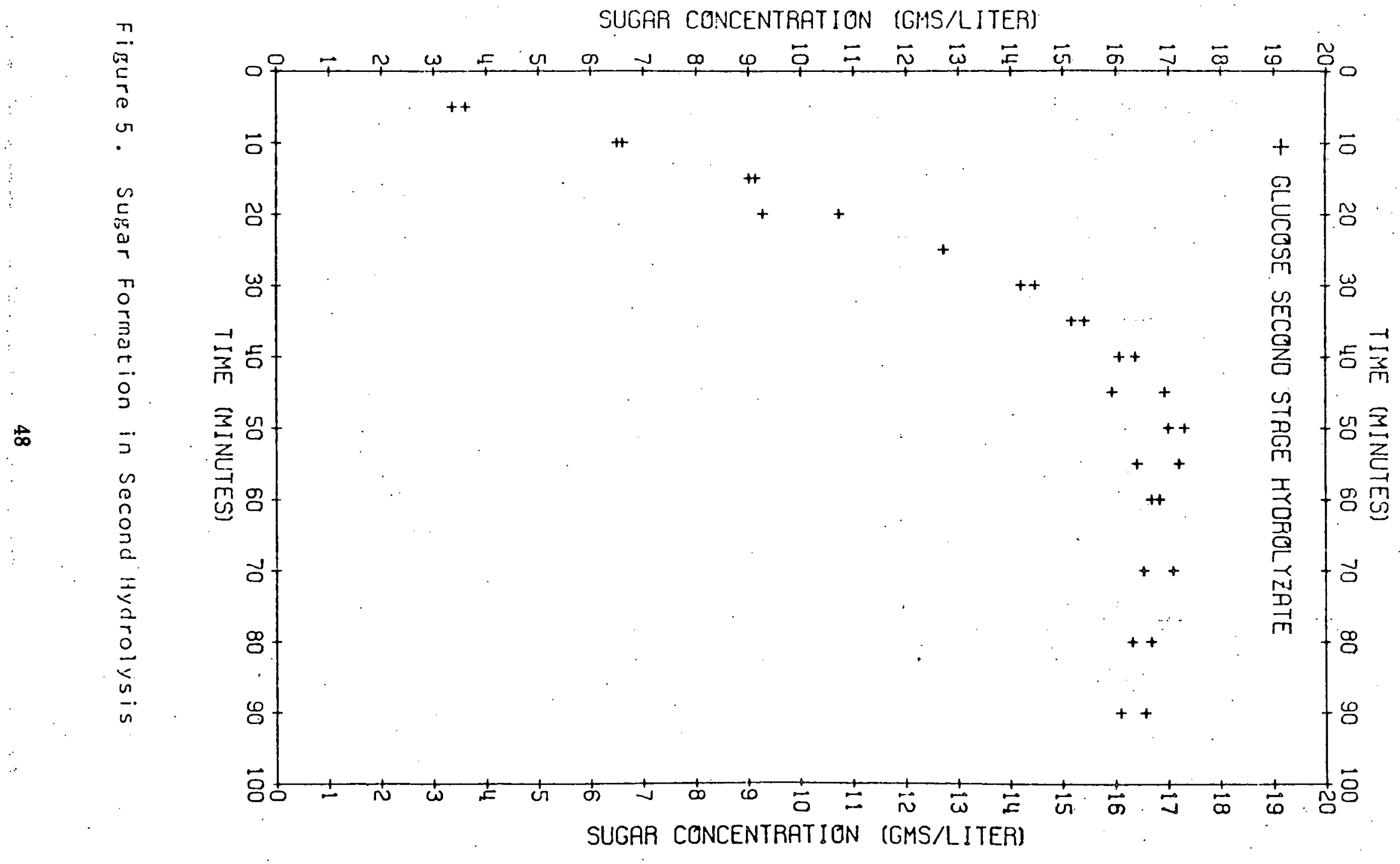

